\title{
Solitary Plasmacytoma of the Zygoma in a 70-Year-Old Nigerian: A Case Report and Review of Literature
}

\author{
Obitade S. Obimakinde ${ }^{*}$, Olufemi J. Taiwo ${ }^{2}$, Ahmed O. Lawal ${ }^{3}$, Akinyele O. Adisa ${ }^{3}$, \\ Victoria N. Okoje ${ }^{4}$, Juwon T. Arotiba ${ }^{4}$ \\ ${ }^{1}$ Department of Oral and Maxillofacial Surgery, Ekiti State University Teaching Hospital, Ado-Ekiti, Nigeria \\ ${ }^{2}$ Department of Anatomic Pathology, Ekiti State University Teaching Hospital, Ado-Ekiti, Nigeria \\ ${ }^{3}$ Department of Oral Pathology, University College Hospital, Ibadan, Nigeria \\ ${ }^{4}$ Department of Oral and Maxillofacial Surgery, University College Hospital, Ibadan, Nigeria \\ Email: ${ }^{*}$ tasky111@yahoo.com
}

Received 6 April 2014; revised 4 May 2014; accepted 3 June 2014

Copyright @ 2014 by authors and Scientific Research Publishing Inc.

This work is licensed under the Creative Commons Attribution International License (CC BY).

http://creativecommons.org/licenses/by/4.0/

(c) (i) Open Access

\begin{abstract}
Purpose: Solitary bone plasmacytoma [SBP] is a localised variant of plasma cell tumor which commonly affects the axial skeleton but rarely found in the maxillofacial region. We hereby report an unusual case of solitary plasmacytoma of the right zygomatic bone in a 70-year-old Nigerian. Case Report: The patient presented with a painless right zygomatic swelling of 2 years duration. Examination showed that the swelling was of mixed consistency [mostly bony but firm in some areas] and it measured about $8 \times 8 \mathrm{~cm}$. Radiographic examination revealed an osteolytic lesion over the right zygoma with involvement of the apex and lateral wall of the antrum. An initial working diagnosis of ossifying fibroma was made and the patient was scheduled for surgery. Histological staining with $\mathrm{H} \& \mathrm{E}$ and immunohistochemistry of the surgical specimen however confirmed a diagnosis of SBP. Serum monoclonal protein and Bence Jones proteinuria was negative throughout the follow up period. Conclusion: SBP of the maxillofacial region is amenable to surgery combined with postoperative radiotherapy. However, prognosis can be worsened with tumor recurrence or dissemination into MM. Thus patients with SBP must be closely followed up after treatment so that immediate therapeutic steps can be taken if recurrence or systemic dissemination is encountered.
\end{abstract}

\section{Keywords}

Solitary Plasmacytoma, Myeloma, Zygoma

\footnotetext{
${ }^{*}$ Corresponding author.
} 


\section{Introduction}

Plasmacytoma is a clonal neoplastic proliferation of plasma cells which can manifest as diffuse myeloma with systemic involvement [plasma cell myeloma or multiple myeloma], monoclonal gamopathy of undetermined significance [MGUS] or as a variant of plasma cell myeloma or non-secretory myeloma [1]-[3]. On the other hand, localised neoplastic proliferation of plasma cells presents as solitary bone plasmacytoma [SBP] or extramedullary plasmacytoma [4] [5]. Occurrence of these lesions in the oral and maxillofacial region either as a solitary plasmacytoma or as part of systemic involvement is very rare [2] [5]-[7]. The incidence of these lesions is said to have a peak period in the $6^{\text {th }}$ decade of life with the lesion more common among the blacks [8] [9]. Presence of serum or urinary monoclonal paraproteins [M proteins] is a diagnostic indicator of solitary Plasmacytoma, however, tissue biopsy for histopathology remains the gold standard since M proteins are undetectable in either urine or blood in nearly half of cases of SBP [8] [10].

Solitary bone plasmacytoma [SBP] occurs commonly in the spine and other parts of axial skeleton but only $4 \%$ of it is said to occur in the oral and maxillofacial region [7]. Chang et al. [10] postulated that the lesion is twice as common in the spine as other bones in the body. While SBP is known to constitute less than 10\% of plasma cell dyscrasias, it is however a known precursor of multiple myeloma [MM] as more than 50\% of SBP patients have been reported to undergo systemic dissemination into MM [11]-[13]. Presence of abnormal serum immunoglobulin free light chain or relapse of treated solitary lesion are indicators of tumor progression to MM [12].

Very little has been reported regarding plasmacytomas in the oral and maxillofacial region and studies cited were mostly in the foreign literature. The dearth of publications from the African literature informed the need to report our experience with management of the only case of SBP of the maxillofacial region that presented at our institution.

\section{Case Report}

A 70-year-old farmer presented at the Oral and Maxillofacial Surgery clinic of Ekiti State University Teaching Hospital, South-western Nigeria in May 2009. The presenting complaint was a painless right zygomatic swelling of 2 years duration. There was no previous history of surgery or any medical intervention of note. Physical examination revealed an oval, well circumscribed, slightly tender $8 \mathrm{~cm} \times 10 \mathrm{~cm}$ firm swelling over the right zygomatic region (Figure 1). There was an area of skin pigmentation overlying the swelling. There was no history of nasal discharge, the overlying skin was intact and the patient's vision was not affected by the mass. Intra oral examination did not reveal any abnormality. Plain radiograph of the right zygoma showed an area of patchy opacity around the region with diffuse opacification of the upper half of right maxillary sinus.

Routine blood investigations revealed a haemoglobin count of $13 \mathrm{mg} / \mathrm{dl}$, total serum protein of $6.2 \mathrm{~g} / \mathrm{dl}$ and a normal electrolyte and urea count. Patient's urine analysis did not reveal proteinuria. An initial assessment of ossifying fibroma was made and the patient was scheduled for biopsy under general anaesthesia. A decision was taken with the patient to carry out complete excision if the lesion was found to be well encapsulated during examination under anaesthesia. On $22^{\text {nd }}$ June 2009, patient was taken to the operating theatre and excisional biopsy was carried out under general anaesthesia via a modified Al-Kayat access incision. Figure 2 shows the postoperative appearance of the patient. A solid mass of well circumscribed lesion was excised and the histology of the specimen confirmed a diagnosis of solitary plasmacytoma (Figure 3). Tissue characterisation with immunohistochemistry was positive for SBP (Figure 4). The patient has since been followed up after excision and there was no sign of tumor dissemination or recurrence. Also periodic laboratory analysis of patient's urine and blood sample did not reveal presence of monoclonal gamopathy or Bence Jones protein.

\section{Discussion}

Plasmacytomas, particularly SBP are very rare in the oral and maxillofacial region and this may account for the dearth of literature on their occurrence in this part of the body [1] [14]. SBP occurs most commonly among the elderly population which is reflected in the demography of the patient in our case report. It is also said to be commoner in male than female with a ration of 2:1 [8]. It characteristically present with a progressive swelling which may be associated with pain and nerve palsy especially in lesions involving base of skull and vertebrae.

Radiographically, SBP has been reported to have an appearance which varies from unilocular to multilocular lytic lesion without periosteal reaction [8] [11] [12]. However, we observed an area of patchy opacities and readiolucencies which is characteristic of a fibroosseous lesion of the facial bone. Based on this, we erroneously 


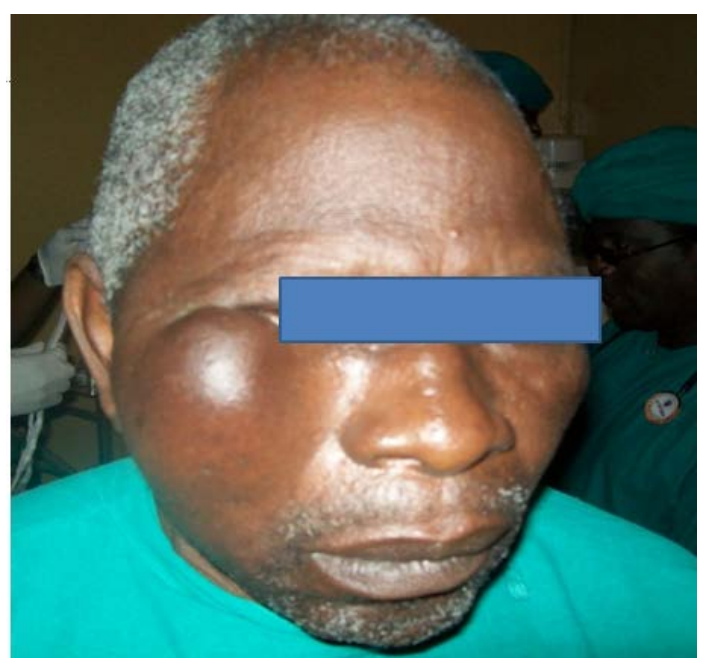

Figure 1. Patient with the tumor on the right zygoma.

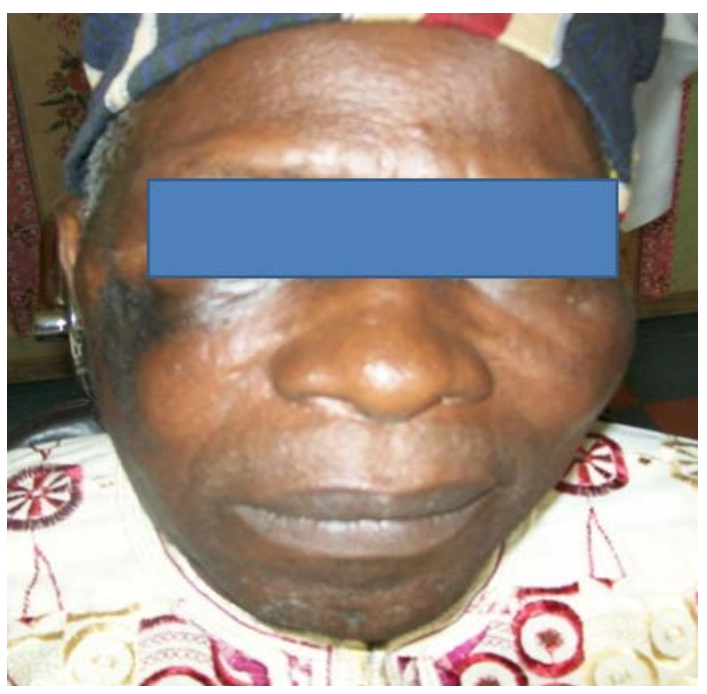

Figure 2. The patient after surgery.

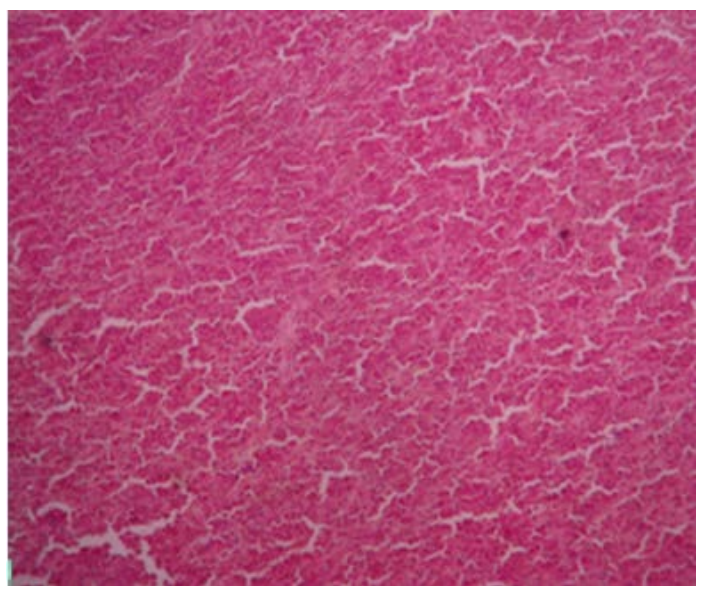

Figure 3. A photomicrograph showing sheets of plasma cells at varying degrees of differentiation with minimal intervening stromal component. H \& E (100×). 


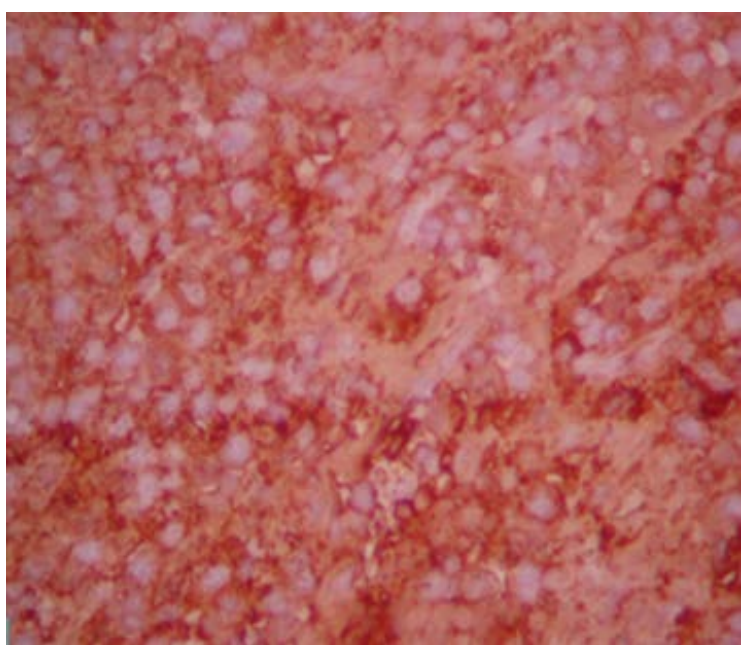

Figure 4. Immunohistochemistry with rabbit monoclonal Lambda light chain antibody [DakoCytomation, USA] showing +3 staining $(400 \times)$.

made a working diagnosis of ossifying fibroma since SBP is not a commonly encountered maxillofacial tumor. Serum or urine M protein which is a diagnostic test was negative in our patient. This could be partly due to the fact that nearly half of SBPs do not show positive Bence Jones proteinuria nor presence of paraproteins in the blood [1]-[3] [7]. Positive M proteins either in the blood or urine is regarded as a predictor of tumor progression to MM [8] [10] [12] [14].

Histology remained the most reliable diagnostic test for plasmacytomas and the diagnosis of SBP was confirmed following excisional biopsy. A solid mass of well encapsulated tumor was excised following surgical access. Although radiotherapy remained the first line of management for plasmacytomas, other authors have advocated surgery for large solitary lesions with or without post operative radiotherapy [1] [2] [7] [8]. In line with this protocol, our patient was referred for radiotherapy after confirmation of histological diagnosis of SBP following surgery.

Progression of SBP to MM has been discussed in the literature and about half of patients with SBP were reported to have tumor dissemination into multiple myeloma [1] [3] [13] [14]. Indicators for dissemination to MM includes low level of uninvolved immunoglobulins, disease involving axial skeleton, older age group, tumour greater than $5 \mathrm{~cm}$ in diameter and persistent $\mathrm{M}$ protein in blood or urine after treatment [8]. We have monitored the patient for over 2 years after surgery and there was neither recurrence of lesion nor dissemination into MM. Furthermore, periodic urinary and blood investigation for $\mathrm{M}$ protein at 6 monthly intervals was negative throughout the follow up period. Chang et al. [10] suggested that tumor dissemination usually occur within 2 years after treatment of SBP and tumors are unlikely to progress to MM after this period. Based on the foregoing, we concluded that the probability of dissemination in our patient is very unlikely.

\section{Conclusion}

SBP of the maxillofacial region is very rare and it runs a relatively benign course. The tumor was found to be amenable to surgery combined with postoperative radiotherapy. Prognosis can be worsened with tumour recurrence or dissemination into MM. Thus SBP cases must be closely followed up after treatment so that immediate therapeutic steps can be taken if recurrence or systemic dissemination is encountered.

\section{References}

[1] Rao, K., Priya, N.S., Umadevi, H.S., Smitha, T., Reshma, V. and Grace, S.A. (2011) Bone Plasmacytoma of the Maxilla: A Rare Case Report. International Journal of Clinical Dentistry, 2, 37-40.

[2] Gupta, A. and Bansal, P. (2011) Mandibular Swellimg —Can It Be Multiple Myeloma? Indian Journal of Dental Sciences, 3, 25-27.

[3] Dimopolous, M.A., Goldstein, J., Fuller, L., Delasalle, K. and Alexanian, R. (1992) Curability of Solitary Plasmacy- 
toma of Bone. Journal of Clinical Oncology, 10, 587-590.

[4] Serena, M. and Pierpaolo, D.M. (2010) Solitary Plasmacytoma of the Jaw. Journal of Blood Medicine, 1, 33-38.

[5] Epstein, J.B., Voss, N.J. and Stenenson-Moore, P. (1984) Maxillofacial Manifestations of Multiple Myeloma. An Unusual Case and Review of Literature. Oral Surgery Oral Medicine Oral Pathology, 57, 267-271.

[6] Das, S.K., Saha, S., Bhowmic, A.K., Mukhejee, S. and Banerjee, S. (2004) Maxillary Swelling-A Rare Presentation of Solitary Plasmacytoma. Indian Journal of Otolaryngology and Head \& Neck Surgery, 56, 213-215.

[7] Agostini, T., Sacco, R., Bertolai, R., Acocella, A. and Lazzeri, D. (2011) Solitary Plasmacytoma of the Jaw. Journal of Craniofacial Surgery, 22, 2-10. http://dx.doi.org/10.1097/SCS.0b013e31822ec79a

[8] Rodriguez-Caballero, B., Sanchez-Santolino, S., Garcia-Montesinos-Perea, B., Garcia-Reija, M.F., Gomez-Roman, J. and Saiz-Bustillo, R. (2011) Mandibular Solitary Plasmocytoma of the Jaw: A Case Report. Medicina Oral Patologia Oral y Cirugia Bucal, 16, 647-650. http://dx.doi.org/10.4317/medoral.16952

[9] Dimopolous, M.A., Moulopoulos, L.A., Maniatis, A. and Alexanian, R. (2000) Solitary Plasmacytoma of Bone and Asymptomatic Multiple Myeloma. Blood, 96, 2037-2044.

[10] Chang, M.Y., Shih, L.Y., Dunn, P., Leung, W.M. and Chen, W.J. (1994) Solitary Plasmacytoma of Bone. Journal of the Formosan Medical Association, 93, 307-402.

[11] Anil, S. (2007) Solitary Plasmacytoma of the Maxilla—A Case Report and Review of the Literature. General Dentistry Journal, 55, 39-43.

[12] Miller, F.R., Lavertu, P., Wanamaker, J.R., Bonafede, J. and Wood, B.G. (1998) Plasmacytomas of the Head and Neck. Otolaryngology—Head and Neck Surgery, 119, 614-618. http://dx.doi.org/10.1016/S0194-5998(98)70021-X

[13] Mustoe, T.A., Fried, M.P., Goodman, M.L., Kelly, J.H. and Strome, M. (1984) Osteosclerotic Plasmacytoma of the Maxillary Bone [Orbital Floor]. Journal of Laryngology and Otology, 98, 929-938. http://dx.doi.org/10.1017/S0022215100147735

[14] Canger, E.M. and Celenk, P. (2007) Mandibular Involvement of Solitary Plasmacytoma: A Case Report. Medicina Oral Patologia Oral y Cirugia Bucal, 12, 7-9. 
Scientific Research Publishing (SCIRP) is one of the largest Open Access journal publishers. It is currently publishing more than 200 open access, online, peer-reviewed journals covering a wide range of academic disciplines. SCIRP serves the worldwide academic communities and contributes to the progress and application of science with its publication.

Other selected journals from SCIRP are listed as below. Submit your manuscript to us via either submit@scirp.org or Online Submission Portal.
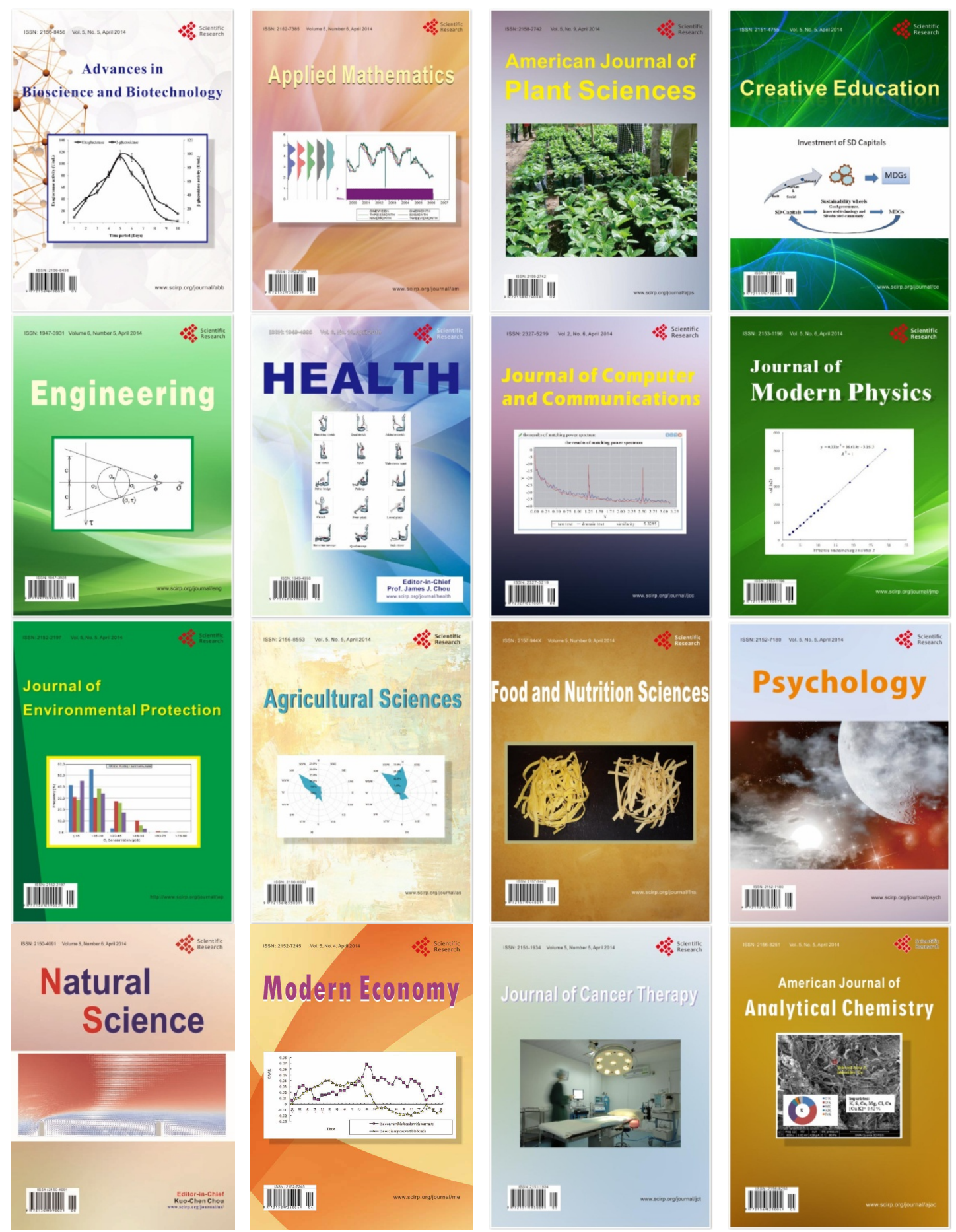